\title{
Atividades com Comunicação \& Educação Ano XII - n. 2
}

Ruth Ribas Itacarambi

Doutora pela Faculdade de Educação da USP.

Educadora e pesquisadora do CAEM - Centro de Aperfeiçoamento do Ensino da Matemática do IME-USP. Professora da FOC - Faculdade Osvaldo Cruz. Membro da Equipe SiteEducacional.

E-mail:ruthri@uol.com.br

Trabalhar com educação na sociedade contemporânea é um exercício de equilibrista: de um lado a sociedade, em que a expansão dos telefones celulares é mais valorizada que a criação de empregos e de moradia; e, de outro, a crise nas relações humanas gerando a violência que se reflete na escola e coloca o dilema de como alguém pode aprender se teme por sua segurança, sua integridade pessoal ou simplesmente por seus bens.

A educação enfrenta no cotidiano a contradição entre os valores que afirma e o que acontece no ambiente em que os jovens vivem. Não é preciso estar nas regiões de conflito para perceber que a verdade, a justiça, o respeito ao outro, a liberdade, a não-violência, os direitos humanos de adultos e crianças são muitas vezes fórmulas vazias. $\mathrm{O}$ artigo $\mathrm{Um}$ filme com muitas portas - entrevista com Carlos Império Hamburger - resgata um período da história brasileira e apresenta aspectos da sociedade na década de 1970. A videografia desta edição complementa tal reflexão, ao propor um exercício de descoberta da história ao relacionar informações, memória, documentos, pesquisa histórica, linguagens, pontos de vista e ficções na análise dos filmes Lamarca e Zuzu Angel.

Os meios de comunicação mostram situações da sociedade em que a violência atinge formas extremas. Essa violência é manchete, fascina e amedronta, gera protestos na comunidade. Aspectos dessa crise são apontados no artigo Imigrantes nos media portugueses: representações das minorias no início do milênio, de Isabel Maria Ribeiro Ferin da Cunha, que, na perspectiva da imprensa e da televisão, apresenta formas de discriminação e exclusão, com base nas origens étnicas e aptidões ante o trabalho e a produtividade.

A crise na educação se reflete não só nos baixos índices de desempenho dos jovens nos diferentes instrumentos de avaliação, mas na exclusão da maioria deles ao acesso às informações essenciais para viver com dignidade no milênio, como o domínio das habilidades fundamentais de ler, escrever e fazer cálculos; tais habilidades preparam o jovem para entender e interferir no seu meio 
comunicação \& educação • Ano XII • Número 2 • maio/ago 2007

ambiente, na história de seu país e nas mudanças tecnológicas da sociedade. O artigo A ferramenta wiki: uma experiência pedagógica, de Mayra Rodrigues Gomes, apresenta uma ferramenta da internet para ser usada em sala de aula: a wiki: Trata-se de uma coleção de páginas interligadas que, cada uma delas, pode ser visitada e editada por qualquer pessoa, trazendo desse modo a tecnologia como um novo cenário para a educação.

Alfabetizar os jovens nas diferentes linguagens é a função da escola, que ainda hoje centra seu trabalho pedagógico na linguagem escrita. As diferentes linguagens relacionam as culturas e, entre elas, a cultura popular, que mais cedo ou mais tarde acaba influenciando e permanecendo na história da humanidade. A relação entre cultura popular e mídia televisiva é tratada no artigo Porque Hoje é dia de Maria, todos os dias são dias de Maria, de Marly C. B. Vidal e Jane Marques.

A formação do jovem para a cidadania em busca de sua humanização, além de significar sua inserção no mundo do trabalho, das relações sociais e da cultura no âmbito da sociedade, também mostra que ter acesso à realidade contemporânea, por meio de mediações as mais diversas, como a mídia, ajuda na construção de significados sociais e interfere nas decisões, atitudes do cotidiano e do pensamento crítico. A recepção crítica dessas mediações é tratada nos artigos A publicidade nos livros didáticos do Ensino Médio, de Maria Aparecida Baccega e Denise de Oliveira Freire, e $O$ texto publicitário como suporte pedagógico para a construção de um sujeito crítico, de Tânia Márcia Cezar Hoff.

As atividades com os artigos desta edição da revista têm como propósito apresentar sugestões para serem desenvolvidas em sala de aula, discutindo as diferentes linguagens na sociedade contemporânea e sua presença na educação, o resgate do diálogo entre a cultura popular e a trama ficcional televisiva, e o papel das mídias na formação de opinião, criando estereótipos sobre as comunidades e o texto publicitário: a mídia divulga informação, não conhecimento.

\section{PRIMEIRA ATIVIDADE}

\section{As diferentes linguagens no conhecimento de um período da história}

A atividade objetiva discutir como diferentes linguagens permeiam a educação, tendo como primeiro referencial a linguagem cinematográfica e sua relação com a televisiva; em seguida, o computador e o teatro. $\mathrm{O}$ artigo Um filme com muitas portas traz a entrevista de Carlos Império Hamburger, diretor do filme $O$ ano em que meus pais saíram de férias, o qual emociona o público com a história de um menino deixado no apartamento do avô, no bairro do Bom Retiro, reduto de imigrantes judeus, às vésperas da Copa do Mundo de 1970.

A atividade que propomos pode ser trabalhada nos diferentes anos do Ensino Básico e, abrangendo um importante período da história do Brasil, organiza-se na seguinte seqüência didática: 
Atividades com Comunicação \& Educação • Ruth Ribas Itacarambi

1) Realizar uma seção de cinema com os alunos. Como o filme já está em vídeo, torna-se mais fácil, embora a saída para ir ao cinema seja recomendada, ou seja, para mostrar aos alunos diferentes espaços de conhecimento.

2) Elaborar um roteiro para o registro:

- do momento histórico em que se passa o filme;

- das relações entre as pessoas, identificando sua cultura através das comidas, da vestimenta, das opiniões etc.; e

- da presença da escola na comunidade.

3) Sintetizar os registros, em sala de aula, destacando o momento histórico em que se passa o filme, relacionando-o com os conteúdos de história trabalhados em sala de aula sobre esse período.

Em grupo, os alunos do Ensino Médio podem pesquisar as Copas do Mundo em que o Brasil participou, fazendo um levantamento dos resultados dos jogos e das características principais do momento histórico em que aconteceram, como os índices de analfabetismo e violência, as taxas de desemprego e a presença da televisão.

Propor a leitura da entrevista, discutindo algumas questões colocadas para o entrevistado:

- O cinema brasileiro oferece um retrato preconceituoso do Brasil ou ajuda a transmitir esse preconceito?

- Você acredita na convivência racial e religiosa entre os diferentes segmentos, tratados no filme de forma positiva?

- Como você vê a cultura brasileira?

- Como você entende a presença da televisão na formação de opinião dos jovens?

- Hoje em dia, as câmeras digitais e os celulares estão colocando em crise o conceito de imagem. No que a imagem está se transformando na atualidade?

Os alunos deverão refletir sobre estas questões, discutir as respostas do entrevistado e manifestar suas opiniões.

$\mathrm{Na}$ discussão das questões, o professor pode propor que os alunos produzam, em grupo, um texto de forma interativa, tal como é apresentado no artigo A ferramenta wiki, não apenas explorando os recursos do Word, mas de um hipertexto, ou seja, que se defina pela dinâmica de um percurso em que diversos tipos de informação estejam presentes, como imagem, vídeo e, se possível, som formando uma rede. Para orientar o trabalho, o professor poderá apresentar para os alunos uma síntese do artigo e mostrar diversas experiências com ambientes de aprendizagem na internet e de construção de textos coletivos; para isso, precisará contar com o processador de texto na sala de informática e recursos da internet. Os alunos poderão consultar o que caracteriza a ferramenta wiki e contribuir com conteúdos. 
comunicação \& educação • Ano XII • Número 2 • maio/ago 2007

Como apoio para o entendimento do momento histórico em que se passa o filme de Hamburger, o professor poderá sugerir que os alunos assistam, também, aos filmes: Zuzu Angel e Lamarca, analisados na videografia.

$\mathrm{O}$ artigo Que sabemos nós de nós mesmos?, de Renata Pallottini, dá continuidade à reflexão sobre este período sombrio da história brasileira e sobre a violência que gerou na sociedade, mas agora na perspectiva do teatro, com a presença determinante da censura na criação do texto teatral.

1) Solicitar que os alunos façam a leitura do depoimento, ressaltando os pontos comuns com a temática dos filmes assistidos.

2) Pedir que os alunos registrem como a censura, na visão da autora, funcionava naquela época.

3) Comentar o depoimento da autora no final do artigo: "Mas hoje, quando o fantasma da censura, qualquer que seja o seu novo apelido, se nos apresenta outra vez, precisamos estar alertas. Não é de censura que precisamos. É de liberdade, honestidade, decência, recursos para a educação, respeito à lei...”.

\section{SEGUNDA ATIVIDADE}

\section{O diálogo entre a cultura popular e a trama ficcional televisiva}

No artigo Porque Hoje é dia de Maria, todos os dias são dias de Maria, a autora reflete sobre a série para televisão Hoje é dia de Maria, que retoma histórias populares entremeadas de fantástico e recriadas a partir da oralidade. $\mathrm{O}$ popular como fator determinante das imagens e da concepção artística explicaria a resistência ao existente e ao estabelecido como regra. É uma outra voz, a da literatura popular que narra nossa história, nossos mitos e lendas, apresentando o homem na rua, na praça, na cidade, no campo; vivendo, enfim.

A atividade que propomos tem a seguinte seqüência didática:

1) Solicitar que os alunos leiam o artigo, respondendo às questões apresentadas.

- Como a autora caracteriza a cultura popular e que manifestações artísticas populares são apresentadas no texto?

- Como a autora mostra o produto televisivo da história Hoje é dia de Maria?

- Quais são os recursos de imagem e de discurso retratados no artigo?

- Como a autora relaciona a trama ficcional televisiva com a linguagem do teatro?

- A leitura do artigo permite o conhecimento da trama tratada na minissérie? 
Atividades com Comunicação \& Educação • Ruth Ribas Itacarambi

2) Sintetizar as respostas dos grupos e registrá-las em um painel na sala de aula.

3) Solicitar que os alunos, em grupo, façam uma pesquisa sobre as principais manifestações culturais de sua cidade: festas, músicas, comidas, objetos etc. Com o registro das pesquisas dos alunos, o professor pode voltar a discutir as questões propostas para a leitura do artigo, particularmente na concepção da cultura popular.

Os alunos poderão assistir ao DVD com o filme Hoje é dia de Maria, que está disponível no mercado, ou acessar o site da globo ${ }^{1}$ e consultar os assuntos tratados nos diferentes capítulos, vivenciando um hipertexto. Para subsidiar o trabalho do professor, sugerimos a leitura do artigo de Paiva ${ }^{2}$, que tem como objetivo instigar um debate nos campos da estética e arte tecnológica, sociologia da mídia e comunicação educativa.

\section{TERCEIRA ATIVIDADE}

\section{O papel da imprensa e da televisão na criação de estereótipos}

$\mathrm{O}$ artigo Imigrantes nos media portugueses: representações das minorias no início do milênio faz um balanço das imagens e representações nas mídias, da imigração e das minorias étnicas em Portugal. Em sua análise, a autora leva em consideração fatores como o esgotamento do modelo econômico presente em projetos de obras públicas e privadas que geravam empregos, o contexto europeu e a globalização da economia, particularmente na expansão da televisão a cabo.

A atividade que propomos tem a seguinte seqüência didática:

1) Conversar com os alunos sobre o que é discriminação, quais as mais comuns na sua comunidade, se estão presentes no seu cotidiano e se percebem a existência dela nas informações veiculadas em jornais e nos programas de televisão.

2) Solicitar que os alunos, em grupo, façam uma pesquisa em sua comunidade sobre as discriminações que apontaram na sala de aula, e que busquem saber a opinião dos entrevistados sobre as informações das mídias.

3) Sintetizar as discriminações apontadas e discutir o modo como as mídias impressa e televisiva tratam o assunto, registrando em um painel.

4) Propor a leitura do citado artigo, tendo como panorama as questões relacionadas à:

- audiência e à ética no jornalismo;

- cobertura jornalística na imprensa e na TV sobre as temáticas crime e violência;

- imagem do jovem da periferia; e

- imagem da mulher.

1. <http://hojeediademaria.globo.com/>. Acesso em: 2 abr. 2007.

2. PAIVA, Cláudio Cardoso. Epifanias do sublime, do trágico e do maravilhoso na minissérie: Hoje é dia de Maria. Universidade Federal da Paraíba. Disponível em: <http://bocc.unisinos.br/ pag/paiva-claudio-epifania-do-sublime.pdf>. Acesso em: abr. 2007. 
comunicação \& educação • Ano XII • Número 2 • maio/ago 2007

5) Sintetizar cada questão e comparar com as considerações apontadas no painel e suas conseqüências na construção da imagem dos jovens para a sociedade.

\section{QUARTA ATIVIDADE}

\section{O texto publicitário: a mídia divulga informação, não conhecimento}

$\mathrm{O}$ artigo A publicidade nos livros didáticos do Ensino Médio discute a importância da publicidade na formação do imaginário e na práxis do cotidiano no campo da Comunicação. Na educação formal os livros didáticos de Português, com intenção de aproximar-se do dia-a-dia dos alunos, têm inserido em seus textos anúncios publicitários, matérias de jornais, capas de revista entre outras formas de atuação da mídia. A análise dos conteúdos desses livros no artigo mostra que a publicidade neles presente apresenta produtos que não fazem parte do imaginário dos jovens e não constituem prioridade de consumo nem representam a aproximação desejada da escola ao cotidiano desses jovens.

Esta atividade é mais adequada para os alunos do Ensino Médio e está organizada na seguinte seqüência didática:

1) Solicitar que os alunos consultem o livro didático de Português adotado, verificando a presença de anúncios publicitários e registrando a página, o veículo da mídia do qual foram retirados e os produtos anunciados.

2) Fazer uma síntese das informações, montando um quadro, e pedir que os alunos identifiquem dentre os produtos apontados quais eles consomem ou gostariam de consumir.

A leitura do artigo pode subsidiar o professor sobre os diferentes modos de utilização das publicidades nos livros, os veículos onde as publicidades foram apresentadas e os principais produtos anunciados. Com estes dados, o professor poderá organizar um quadro e discutir com os alunos as semelhanças com os itens do livro didático adotado, o significado dos anúncios para trabalhar os conteúdos da língua portuguesa e a identificação dos jovens com as mensagens dos anúncios.

$\mathrm{O}$ artigo $O$ texto publicitário como suporte pedagógico para a construção de um sujeito crítico da continuidade à reflexão, pois discute a construção do conhecimento na escola, o ensino e a aprendizagem como busca da humanização e o saber que nos eleva à condição de cidadãos, incluindo a formação ética e o desenvolvimento da autonomia intelectual.

1) Solicitar que os alunos façam a leitura do artigo, dando especial atenção aos itens:

- Os meios de comunicação podem ser considerados fontes de informação para a construção do conhecimento? 


\section{Atividades com Comunicação \& Educação • Ruth Ribas Itacarambi}

- O que é necessário para a construção de um conhecimento?

- Tendo como perspectiva a formação crítica do cidadão, como utilizar o texto publicitário na sala de aula?

2) Sintetizar as questões e opiniões dos alunos sobre a leitura do artigo, em especial dos itens apontados. Comparar com a síntese da leitura anterior.

Resumo: As atividades com os artigos desta edição da revista têm como propósito apresentar sugestões para serem desenvolvidas em sala de aula, discutindo as diferentes linguagens na sociedade contemporânea e sua presença na educação, o resgate do diálogo entre a cultura popular e a trama ficcional televisiva, o papel das mídias na formação de opinião, ao criar estereótipos sobre as comunidades, e o texto publicitário: a mídia divulga informação, não conhecimento.

Palavras-chave: linguagem, cultura popular, ficção, texto publicitário, educação.
Abstract: The activities with this issue's articles are suggestions to be developed in classroom: the discussion of the existence of different languages in contemporary societies and its presence in education, the rescue of dialog between popular culture and the TV story plot, the role of mass media in opinion formation by creating stereotypes on communities, and the advertisement text - media disclosures information, not knowledge.

Keywords: language, popular culture, fiction, advertisement text, education. 